\title{
Guidance for Medical Ethicists to Enhance Social Cooperation to Mitigate the Pandemic
}

\author{
Kevin Powell ${ }^{1} \cdot$ Christopher Meyers $^{2}$
}

Accepted: 28 January 2021 / Published online: 15 February 2021

(c) The Author(s), under exclusive licence to Springer Nature B.V. part of Springer Nature 2021

\begin{abstract}
The Covid-19 pandemic has presented major challenges to society, exposing preexisting ethical weaknesses in the modern social fabric's ability to respond. Distrust in government and a lessened authority of science to determine facts have both been exacerbated by the polarization and disinformation enhanced by social media. These have impaired society's willingness to comply with and persevere with social distancing, which has been the most powerful initial response to mitigate the pandemic. These preexisting weaknesses also threaten the future acceptance of vaccination and contact tracing, two other tools needed to combat epidemics. Medical ethicists might best help in this situation by promoting truth-telling, encouraging the rational adjudication of facts, providing transparent decision-making and advocating the virtue of cooperation to maximize the common good. Those interventions should be aimed at the social level. The same elements of emphasizing cooperation and beneficence also apply to the design of triage protocols for when resources are overwhelmed. A life-stages approach increases beneficence and reduces harms. Triage should be kept as simple and straightforward as reasonably possible to avoid unwieldly application during a pandemic.
\end{abstract}

Keywords COVD-19 · Virtue Ethics · Triage committee

The pandemic of Covid-19 has presented a grave challenge to public health, threatening millions of deaths worldwide, including at least hundreds of thousands within the United States. Hospitals, laboratories, and grocery stores have mobilized people and equipment to meet the challenge. Nurses, doctors, therapists and cleaning staff have assumed risks. Some have died. Stories abound of heroic work. Nothing in this

Kevin Powell

kpowell@alum.mit.edu

1 Saint Louis University, Saint Louis, MO, USA

2 California State University, Bakersfield, Kegley Institute of Ethics, Bakersfield, CA, USA 
essay critiquing policy choices should in any way detract from the admiration and gratitude for those efforts.

Presented with an enormous challenge with many unknowns, one should naturally expect both strengths and weaknesses in the various responses that have been made so far. It is too early to assess all of the long-term outcomes of these many interventions. ${ }^{1}$ However, it is appropriate for some retrospection to guide how our society continues forward. The pandemic has exposed weaknesses in the social fabric of modern civilization that intensify the magnitude and the disparities in where and to whom the greatest harm is being suffered.

This essay will identify, categorize and assess those factors, focusing on ethics, social values, and human behavior rather than the technical aspects of medical treatment and epidemiology. Distrust in government and a lessened authority of science to determine facts have both been exacerbated by the polarization and disinformation enhanced by social media. These preexisting issues have compromised efforts to mitigate the pandemic. Medical ethicists could most effectively address this by focusing on these underlying and divisive social problems. The essay first examines the response to the pandemic at a systems level. Once this macro-level approach is analyzed, the essay will then further elucidate how a similar focus on beneficence and cooperation, rather than rights language, leads to a better micro-level policy for triaging scarce supplies, including ventilators.

\section{Assessing the Response}

The most dramatic response to the pandemic was when medical authorities, based on emerging science and tentative modeling, persuaded the government and the public to institute unprecedented changes to social behavior. These included shutting down "nonessential" businesses, limiting travel and public gatherings, and recommending individuals practice social distancing, strict hand hygiene, intensive cleaning of shared surfaces, and the wearing of masks. These interventions created enormous economic costs, social disruption, and significant secondary harms to public health. The economic costs include a recession, mass unemployment, bankruptcies, and trillion dollar stimulus packages. The interventions also interrupted the education of children and young adults, a determinant of future health and wellness. Medical consequences include postponing elective but important medical services such as surgeries, cancer screenings, and vaccinations (Rosenbaum 2020). There has been increased morbidity and mortality when needed medical services were not delivered because the public was avoiding emergency rooms and doctors' offices due to fear of contagion (Mihaljevic and Farrugia 2020).

\footnotetext{
1 Indeed, the data collection is an ongoing process. Therefore, many references in this essay are articles from reputable, investigative news organizations rather than peer reviewed academic journals. Many journal articles about Covid-19, based on data from China and released early, were obsolete or contradicted before their official print publication in March and April 2020.
} 
The goal was to flatten the curve and an examination of graphs of new cases and deaths plotted versus time shows that the strategy achieved its primary mission (Johns Hopkins University 2020). With the reopening of the economy the pandemic has again grown. The most commonly cited predictive models for the pandemic death toll (Ferguson et al. 2020) looked solely at minimizing deaths from the virus and did not assess all-cause mortality. Those models did not assess increased deaths due to suicide, depression, poverty and unemployment. This narrow focus is common in medical publications and too often means that early articles do not give sufficient attention to complications, negative outcomes or unwarranted economic costs. These failings were, for example, commonly present in early cancer research and in post-menopausal hormone replacement therapy where a one-sided focus historically led to faulty recommendations.

In the case of the Covid-19 pandemic, there are insufficient data to determine whether the lockdown cure was worse than the disease. A valid answer will likely be years down the road and will depend not only on having accurate data, but also on the values assigned to those numbers. For example, how do we comparatively value lives saved-including those, who, because of age and pre-existing conditions, might well have died anyway within the following year- versus clear economic costs and secondary medical harms. Add that many of those latter harms could have occurred without government intervention, as a worried public on their own avoided group settings like restaurants and sporting events, and the cost-benefit analysis becomes extraordinarily complex.

The pandemic is placing enormous strains across all societal sectors and a complete shutdown is unsustainable economically and socially. Some mid-course corrections have been made. For example, businesses that do not involve crowds have reopened. The American Academy of Pediatrics has released guidance strongly reinforcing the importance of in-person teaching for children's learning and social development (American Academy of Pediatrics 2020). Some universities have reopened. The number of cases of Covid-19 has increased as a result of these many changes. Government officials at federal, state, and local levels are monitoring the flare-ups and assessing whether to reimpose restrictions, but the public's willingness to comply has waned.

The pandemic is demonstrating how interdependent people are both in terms of contagion of the virus and in terms of the number of essential workers needed to keep the economy running and food on the table. In national emergencies, the appropriate and productive response of a well-functioning society is to set aside lower priority goals and join together to deal with the existential threats. In these circumstances, the virtue of cooperation becomes more important. Contemporary political divides have, no doubt, made cooperation challenging, but given the nature of this virus and associated economic and political threats, there really is no alternative; we have to come up with shared solutions in which we all give and gain. Achieving this requires agreement on two key items. First, there needs to be agreement on the facts of the situation. Second, there needs to be an agreement on the goals. In the United States, several factors over the last decade have weakened society's ability to agree on either. 


\section{Public's Trust of Science}

A major component of achieving a common plan of action is to agree upon the facts. As Senator Patrick Moynihan is said have stated, "People are entitled to their own opinions, but not to their own facts" (Quote Investigator 2020). In the modern era, science has long served as a secular moderator of facts. This function is embedded in the United States' legal system in the rules of evidence for expert testimony. Journalists also interview and cite scientific authorities. Respect for this function arguably peaked during the moon shot of the 1960's and its decline can be plausibly traced to a number of factors: the democratization of power structures with its concomitant rejection of authority_religious, financial, and scientific; postmodern relativism; mercenary scientists (Oreskes and Conway 2010; Michaels 2008); and health and science illiteracy. The decline has recently been exacerbated by misinformation and polarization enabled by the design of social media.

In March 2020, trust in medical scientists was sufficient to embark upon the major social upheaval of the lockdown though governmental acceptance and individual compliance varied in timing and degree based on politics and geography. The public's initial cooperation with social distancing, face coverings, avoidance of large gatherings, and shuttering of bars and restaurants was vital to a successful flattening of the curve. As the restrictions became increasingly burdensome and public health declarations were politicized, sectors of the population became less cooperative and multiple instances of noncompliance have been associated with subsequent outbreaks. All this motivated the American Association of Medical Colleges (2020) and Johns Hopkins Center for Health Security (Rivers et al. 2020) to call for a "reset" at the end of July. In short, without trust in the information provided by scientists, the public's cooperation has been weaker than it could have been. Lives have been lost as a result.

It is paradoxical for this disinformation to occur in the electronic age. In May 1988, in response to the deadly AIDS epidemic, Surgeon General C. Everett Koop, in an unprecedented act of public health communication, mailed an eight page printed pamphlet to every household in the US providing vetted information about HIV and AIDS. In 2020, despite the ease and low cost of electronic communication, the Internet-through bogus and ideologically skewed "news" sites and especially through Facebook and other social media-has become polluted by so much misinformation, disinformation, and fringe theories that distributing medical truths to the general public has been compromised. The daily White House Task Force briefings have also been widely criticized. The CDC had a playbook (National Security Council 2020) for responding to a pandemic. It contained wisdom gleaned from the 2009 flu epidemic. It was largely ignored (Dale 2020; Harris et al. 2020).

The reduced ability to provide accurate, timely, trusted communication of scientific information is a major weakness in the modern social fabric that has been exposed by the pandemic. Two other related preexisting conditions are vaccine hesitancy and privacy violations in cell phone apps.

Government and health officials have emphasized the hope for a vaccine to eradicate the pandemic. To be effective, the vaccine will need to be widely 
accepted. Besides developing the vaccine and overcoming the hurdles of distributing hundreds of millions of doses, there is the task of soliciting a high degree of cooperation from the public. This will depend on the public's trust in scientists' assessment of the safety and efficacy of the new vaccine(s). So far, polls have shown that 26 to $50 \%$ of people would refuse the vaccine (Cornwall 2020; Reinhart 2020). This reluctance for vaccines preceded the pandemic. In fact, the World Health Organization (2019) in January 2019 listed vaccine hesitancy as one of 10 major global health threats. A public relations campaign is already underway to promote acceptance of a Covid-19 vaccine. PhRMA (Reilly 2020) has a commercial with the tag phrase "Because Science is how we get back to normal." Political pressure on the federal government's top scientific institutions leads Leana Wen (2020) to warn of the public's crisis of confidence in recent recommendations, including those about vaccines. She provides a list of corrective steps emphasizing transparency, independent scientific experts, and timely updates for the public. Anthony Fauci has similarly offered reassurance that politics will not influence approval of a vaccine (Szabo 2020).

Contact tracing is typically the primary means of responding to disease outbreaks. It dominated the response to recent Ebola outbreaks. The size of the Covid19 pandemic has overwhelmed the capacity to do this. Technology companies have touted the possibility of using the ubiquitous cell phone location service as a technological solution to detect recent proximity to an infected person, perform contact tracing and automate notification of individuals exposed to the novel coronavirus. This solution would require near universal downloading of the relevant app(s) onto people's phones. Japan started this in June 2020 (Kyodo 2020). Due to concerns, going back many years, about how the gathered information might be misused (for law enforcement, immigration, advertising, and other privacy violations (FTC 2020)), a significant fraction of the public is reluctant to provide the government or tech companies this level of monitoring of people's whereabouts and activities (Lash et al. 2020; Fowler 2020).

These problems of reduced trust in scientists, disinformation on the Internet, vaccine hesitancy, and privacy violations are all unresolved problems of social ethics that preceded the pandemic. All have or will negatively impact society's response to the pandemic and cost an untold number of lives. While this essay cannot offer a simple, immediate cure for these pre-existing social conditions, identifying root causes and documenting their severity does point to ways to improve outcomes.

\section{Rescue Medicine}

The second major component of cooperation is an agreement on goals. The paradigm of rescue medicine is pervasive in the modern U.S. health care system and has not been adequately addressed by clinical ethics. In rescue medicine, life-saving procedures (for example, surgery, immunotherapy, ICU ventilators) for an identifiable, imperiled patient are highly valued, as are the vast array of imaging technologies needed to support this style of care. Conversely, public health measures to reduce suicide rates and addiction, which cannot be linked to saving the life of a particular 
individual, are not valued as highly in this misguided paradigm. Promotion of wellness is even less valued. Rescue medicine results in a tiered system of unsustainably luxuriant care in teaching hospitals and ICUs for those whose death is imminent. Its prioritization results in inadequate resources for public health, primary care, nursing homes and other facilities for aging adults, and for those with mental health problems. As the studies cited below reveal, the pandemic has exposed and magnified these disparities. Rescue medicine leaves the public falsely believing that intense medical care-for example, hospitalization and ventilators-will more likely save them than personal and communal habits, like handwashing, social distancing, and not going to work when ill.

Rescue care is subject to tunnel-vision: How to best respond to the urgent need right here, right now (Covey 2004). The culture of medicine ingrains the ethos of saving lives and it empowers, even requires, the bedside physician to be most focused on the immediate needs of the patient in front of them. True enough, but the goals and values of rescue medicine distorted the response to the pandemic in a manner that led to many deaths that might have been avoided if a broader public health perspective had been invoked. In response to the pandemic, the United States medical system geared up its capacity, hoping to provide state-of-the-art medical care to everyone whose lives were threatened by the disease. The goal was to identify individuals in extremis and provide them with intensive care and a ventilator. The emphasis is on heroically saving identifiable lives. In one news report, "[Governor Cuomo] added that no one in the state who needed one had gone without a hospital bed or a ventilator. 'I increased the hospital capacity to an extent that we didn't even need,' he said." But in the New York metropolitan area as few as $12 \%$ of elderly patients placed on a ventilator survived to discharge (Cha 2020).

Meanwhile, less attention was paid to public health measures (personal protective equipment, nursing staff ratios, contact tracing, and nursing home management) to reduce contagion among those living in nursing homes and other long-term care facilities. While New York City hospitals managed to avoid rationing ventilators at the bedside, $40 \%$ of Covid-19 deaths in the city were occurring within nursing homes and not at hospitals (New York Times 2020; Barnett and Grabowski 2020). Further, this rescue mentality ignores secondary deaths: the number of deaths recited in daily news reports are confirmed and probable deaths due to the virus but deaths due to an increase in suicide, an increase in violent crime, the delay of medical care for other diseases, and the morbidities of social isolation (alcoholism, drug addiction, domestic abuse) do not factor into these reports, nor do deaths due to economic hardships and unemployment.

The root causes for these policy choices are many and include: long-established training paradigms that teach health care professionals primarily to focus on and attempt to fix immediate problems; the greater emotional toll that comes with (perceived) abandonment of the person in front of you, even on behalf of a person whose distance mutes their pain and suffering; hospital leadership fearing being seen as having failed in their mission of providing care to all who seek help; and the powerful psychological rewards attached to knowing that you have heroically achieved life-saving success in the face of all odds. The result: attention was focused on ventilators and hospital ships rather than nursing homes. Personal protective equipment 
(PPE) was consumed in large quantities for each patient admitted to an ICU, while staff in many nursing homes, assisted living, and other congregant facilities did not have enough PPE available to reduce contagion and avoid the many lives lost there. No authoritative calculations are yet available to determine which allocation would have saved more lives. That absence itself is telling.

Most rationing decisions are not made at bedside. They occur earlier during the budgeting process. For example, a national stockpile held a reserve of PPE. It was consumed during the 2009 flu epidemic but was not replaced (Reinhard and Brown 2020; Contrera 2020). Hospitalists are identifying the myriad root causes of this shortage and have recommendations for future epidemics that include preparedness and more coordination and cooperation among institutions (Lagu et al. 2020).

In short, a medical system dedicated to rescue medicine has had successes in dealing with an overwhelming pandemic. It has also had pre-existing biases that have limited that response. Outcomes measured as total cases and deaths have been more dependent on personal and community actions and non-medical interventions like social distancing, than on the quality of available high-tech rescue care. In a highly contagious pandemic, when the number of cases can quickly grow exponentially, prevention is more efficient than medical treatment.

This critique of rescue medicine also applies to clinical ethics. Similarly reactive in style and tone, much of the ethics work in the early stages of the pandemic was dedicated to designing perfect policies for rationing ventilators and other crisis level care. Meanwhile, prevention and wellness promotion were neglected, as were efforts to enhance trust in scientific authority or to improve science and informational literacy. The now-decades old clinical ethics emphasis on autonomy and individual choice appropriately shifted the paradigm away from paternalism and physiciancentered power, but a pandemic-driven health care emergency reminds us also of the importance of community, cooperation, character, and virtue. Ethicists can foster these values by stressing truthfulness, adjudicating competing facts, and helping clarify community healthcare and justice priorities.

\section{Triage}

None of this is to say that ethicists should ignore triage; rather, they can and should apply those same standards of truthfulness, adjudication and values clarification to triage's difficult moral challenges. For example, a survey of publicly available policies reveals that most were designed to save as many lives as possible, with only limited concern for life-years. And because those whose lives were most in jeopardy skewed older and had threatening co-morbidities, this meant that many hospitals' protocols equally prioritized such persons alongside younger and healthier patients.

The perceived justification for this equivalence is rooted in a deep strand of theological and philosophical thought, eloquently expressed in a recent Joint Statement (Anderson et al. 2020). Speaking against triage approaches that prioritize some patients over others, the authors state, "no such prioritization principles should be allowed to undermine a core conviction of our moral tradition, viz., that the lives of all human beings are of inherent, equal, and indeed incalculable value" (Anderson 
et al. 2020, emphasis added). Because, this view holds, the value of each human life is infinite and cannot be quantified, each is also-regardless of age or health-damaging condition-equally and infinitely worthy.

Such dignity-language has at least profound heuristic import; but however much one might revere the value of human life, it does not follow that life-saving resources must be equally distributed. Where possible or where the immediate exigencies demand it, health care services should certainly look to save all lives. But where that is not possible and where decision-makers have the luxury of time to reflect on hard choices, life-years should be a consideration.

Although this position is often characterized, even denigrated, as strictly utilitarian, it can also be grounded in justice and virtue. What follows are four arguments in defense of this "fair innings" view:

1. Wherever feasible, persons should be given the chance to experience all the stages of life;

2. In the United States at least, social benefits have contributed to older persons being able to enjoy the goods of life;

3. The moral goods at work here are attached to living, not to biological life; and

4. Any attempt to reject a life-years approach by prioritizing persons from historically oppressed communities fails on theoretical and practical grounds.

\section{Life-Stages}

Consider the death of a beloved family matriarch. Having lived a rich life, filled with cherished family relations and an important, societally contributing, career, she is 87 years old when killed by a drunk driver. Her loved ones are emotionally devastated, no doubt, but much greater grief is expended toward her nine-year-old great grandchild, killed in the same accident. Why? "Other things being equal, the young have much more to lose from death than the elderly" (Miller 2020). Ezekiel Emanuel and Alan Wertheimer state it thusly:

Death seems more tragic when a child or young adult dies than an elderly person-not because the lives of older people are less valuable, but because the younger person has not had the opportunity to live and develop through all stages of life ... to be a child, a young adult, and to then develop a career and family, and to grow old.- and to enjoy a wide range of the opportunities during each stage. (Emanuel and Wertheimer 2006, p. 855)

Mildred Solomon et al. (2020) concur. In defending a life-years model as a tiebreaker, they state, "privileging younger patients is justifiable because it's based not on stereotyping or bias against older patients but on equal opportunity and minimizing harm: the younger persons have had less opportunity to experience a full life and therefore would suffer greater harm if they were to die" (Solomon, Wynia and Gostin 2020, p. e27(2)). Govind Persad and Douglas White similarly defend the legality of prioritizing children and further assert that ethically, "Giving pediatric 
patients some priority in access to treatment appeals not only to the value of equality of opportunity to live a complete life but also to the value of reducing disparities" (Antiel et al. 2020, p. 3).

Prioritizing the child does not mean the matriarch is less respected or that she has reduced human dignity. If anything, her history and matriarchal status make her more highly revered. Nonetheless, the sense of loss is greater for the child, precisely because his life was cut short, before he had the chance to experience its stages and to achieve his potential. Emanuel and Wertheimer, citing research by Norman Daniels (1988), suggest a life-years approach aligns with most persons' core ethical sensibilities: "Multiple considerations and intuitions support this ethical principle. Most people endorse this principle for themselves. We would prioritize our own resources to ensure we could live past the illnesses of childhood and young adulthood and allocate fewer resources to living ever longer once we reached old age" (Emanuel and Wertheimer 2006, p. 855).

Granted, intuitions vary on this point and there has been anything but consensus in policy choices. For example, on one hand, California withdrew and revised their initial triage guidelines, in part because of the strong pushback they received for including life-years and likelihood of multi-year survival (Center 2020). Similarly, John Stone argues that a life-years, even a lives-saved, approach is unjust because it compounds historical inequities that disproportionately impact vulnerable populations (Stone 2020, p. 580). On his account, thus, a child could lose out on access to a life-saving resource if put up against an aged person from a community that has historically faced injustices. Persad and White note, furthermore, the demographics that "people from groups who are subject to various forms of disadvantage and social injustice are less likely to live a long life. They are, today, overrepresented in younger age groups and underrepresented in older groups" (Antiel et al. 2020, p. 3).

By contrast, Spain and Italy include advanced age in their criteria, while Switzerland went a step farther, adopting "guidelines that automatically exclude patients above the age of 85 from critical care units and access to a ventilator when there is competition for resources" (Barnes 2020, emphasis added). While these competing perspectives affirm that intuitions vary, the reasons given herein strongly support a life-years approach.

\section{Societally Granted Benefits}

It is not just that the younger person has not had the chance to experience life; it is also that the older person has. Someone in their mid-80s has already exceeded the U.S. average life expectancy by a half-decade, having had, in the process, the opportunity to experience life's goods: loving relationships, health and physical vigor, opportunities for self-improvement through education, culture and the arts, protection from natural and human threats, and the economic security that underpins all of these. Enjoyment of these goods is finite and limited, not just because our bodies deteriorate and relationships fade, but because many of them are dependent on community assets. No doubt, some of the necessary resources are our own-our bodies, our intellect, our will to be productive and to make our and others' lives better. 
Some of it also just falls to dumb luck: being born with a genetic make-up that promotes longevity or being born into a family that motivates the habits of exercise and healthy living. However, the older person has also benefited from a lifetime of community resources such as education, health care, public safety and infrastructure.

One need not take these premises to the conclusion promoted by, for example, John Hardwig that persons have a "duty to die" when they become a burdensome strain on others (Hardwig 1997). A more moderate view is that because older persons have been granted the opportunity to experience life's stages and to enjoy its goods, this should motivate virtuous character traits of gratitude, reparation and generosity. This is in fact reflected in current triage protocols: even those that reject lifeyears as a mandatory criterion reinforce that should older or less-likely-to-survive persons wish to voluntarily forgo use of scarce resources, this will be supported, even applauded, and aggressive palliative measures provided.

This appeal can, in fact, be taken a step further: when there are not enough resources for all, a society may choose to distribute communal resources in a manner that maximizes beneficence while also promoting just outcomes. When faced with the forced choice between those who have achieved a normal life expectancy (80 years) and those just starting out in life (30 and younger) the love and compassion within a just society motivates it to prioritize the latter.

\section{Objections}

There are at least two main critiques of the life-years approach. First, all life is of infinite and incalculable value and thus one cannot say that a child's life is worth more or should be prioritized over an older person's. Second, historical injustices faced by members of oppressed communities create an unfair calculus: they are more likely to die from Covid-19 precisely because economic circumstances force them to take greater risks or because they carry co-morbidities brought about by those oppressive conditions.

\section{The Infinite Value of Life}

Recall the language from the Joint Statement: "No such prioritization principles should be allowed to undermine a core conviction of our moral tradition, viz., that the lives of all human beings are of inherent, equal, and indeed incalculable value" (Anderson et al. 2020). For the sake of argument, accept the problematic ${ }^{2}$ assumption of inherent value, but fully examine the "incalculable" characterization. At no point in history have persons in fact behaved as though human life was so valuable that it outweighed every other moral and economic consideration. We ethically kill other humans who threaten us and for reasons of retributive justice, and we routinely

\footnotetext{
${ }^{2}$ While common to the canon of Western ethics theory, the underlying metaphysics are deeply contested; there are also conceptual ambiguities over such concepts as human life and coherently distinguishing it from other living beings.
} 
weigh the cost of human life against such economic considerations as safer transportation, pollution, and, indeed, health care costs. For instance, the value of a statistical life used by the Environmental Protection Agency is currently about $\$ 9.6$ million, adjusted to 2020 dollars (Conover 2020; EPA 2020).

If, instead, human life is seen to have profound moral worth, a strong, but defeasible, prima facie duty to protect and promote it emerges. When, however, any given human life is in competition with another important moral value, one must do an analysis to determine which should prevail. This will include an evaluation of direct competing goods: for example, is it human life (or lives) versus human life? Justice versus life? Fundamental ideology versus life (think martyrs)?

While, again, there are at least good heuristic reasons to attach value to all human life, the greatest value comes from living, in the connections and activities that bring pleasure, joy, and contentment to ourselves and to our loved ones. That is, life is instrumental to the value found in those things that allow humans, and other animals, to thrive biologically, socially and spiritually.

The range of such connections and activities is diverse, populated by both quantitative and qualitative goods: bodily pleasure, sure, but also the mental, emotional and physical enjoyments provided by a good book, philosophical debate, hugging a child, climbing a mountain, or surfing a wave. Add helping others with their needs, knowing that you have given back to the community, reflecting on the past and hoping for the future, learning a new skill or teaching one to another, and what emerges is a view into necessary capacities. Some are grounded in physical ability and perception, others in the mental; some are accessible to higher order non-human animals. Some require humans' more sophisticated brain structures. But all require cognition: the goods that come from living all require awareness-minimally of pleasure and pain - and of the ability to engage one's environment and the other beings in it. A full explication of how this would translate into an ethical framework is beyond this essay, but it would include such questions as: How much capacity is sufficient? How do others' attachments to the human in question weigh in the evaluation? How do we balance very low capacity human life against higher capacity nonhumans? What are the wider implications of jettisoning "inherent value" rhetoric?

When resources are plenty, modern clinical ethics relies heavily on patient autonomy, often via surrogate or advance directives, to guide shared decision-making about inherent worth and the limits of intensive care. Under a crisis standard of care during a pandemic, health care teams may not have that flexibility and may need to employ a communal set of values. For example, if forced to ration a ventilator between someone in a permanent vegetative state (PVS) and an otherwise previously healthy 20-year-old, morality demands preference for the latter. Here, it is not only that the 20-year-old has not had the opportunity to experience life's stages; it is also that, contrary to the PVS patient, she is capable of experiencing that life.

Some disability groups argue that even the extremes of PVS and a previously healthy 20 year old should be treated as equal: "It is critical that any guidelines or policies for the allocation of scarce resources in California during Covid-19 focus on the ability to benefit from and survive treatment, rather than on traits and statuses that are proxies for disability" (Center 2020, p. 7). That view can be supported only if one accepts that "the lives of all human beings are of inherent, 
equal, and indeed incalculable value" and that therefore no other moral consideration can be brought into the moral evaluation. This paper rejects that framework as untenable; health care professionals as good stewards are obligated to, and justified in, prioritizing their efforts toward sustaining those capacities that allow persons to actively live. This conviction holds in all health care decision-making, particularly when advocacy groups push their own treatment agendas, and was made pressing by the difficult resource allocation decisions wrought by Covid-19.

This paper emphasizes how accommodating various understandings of "inherent moral worth" may be more limited during a crisis. Once the concept is entertained that the inherent moral worth of human life is not infinite and absolute, one has, admittedly, placed one foot on a steep and slippery slope: If society is willing to withhold treatment from someone in a PVS, why not a paraplegic? Or, if a 20 -year-old prevails over a 90 -year-old, how about a 35-year-old versus a 40-year-old? The risk of sliding down this slope is clearly one of the major concerns of groups like DRDEF and their worries are valid, but only to a point: slippery slopes are genuine threats, but not unavoidable ones. One prevents the slide by building hard breaks into policy.

This means drawing these distinctions only at the edges and only during a formally declared Crisis Standard of Care. Hence, when faced with a forced decision, when there are not enough resources to treat everyone, resources should be allocated as follows:

1. Is the treating team reasonably confident that the patient will benefit from the treatment? If not, treatment may be withheld or withdrawn if there are others who would benefit.

2. Is the treating team reasonably confident the patient will survive for at least a few months after hospital discharge? If not, the treatment may be withheld or withdrawn if there are others who will benefit and survive beyond discharge.

3. Does the patient have the capacity for cognitive engagement with the world? If not, the treatment may be withheld or withdrawn if there are others who meet the first two criteria and who have, or will have, such cognitive capacity.

4. Is the patient 85-years-old or older? If so, the treatment may be withheld or withdrawn if there are others who meet the first three criteria and who are at an earlier life state of 65-years or younger

5. From there, rely on the standard triage model of the sort recommended by Maves et al. (2020).

Yes, this means that scarce life-saving resources will be omitted from persons within the exclusionary criteria. But, just as importantly, they will be provided to a 60-year-old with paralysis, or a 15-year-old with Downs Syndrome, or a blind infant, each of whom has ample capacity to thrive. This belies the fear that once any distinctions are drawn, all those with disability will be discounted. Instead, the position defended here heartily embraces that the value attached to human living can be expressed via a tremendously wide range of physical and mental capabilities. It also insists upon safeguards against abuse. 


\section{Historical Injustices}

The second and fourth criteria, above, either exclude or assign negative scoring points to those patients who are less likely to survive in the short term. As data have amply shown, this disproportionately impacts persons from historically oppressed communities, either because systemic failures in health care have left them with threatening co-morbidities, or because their economic standing forces them into riskier work and living circumstances (Stone 2020). "The coronavirus found, exploited, and widened every inequity that the U.S. had to offer.... Far from being a 'great equalizer,' the pandemic fell unevenly upon the U.S., taking advantage of injustices that had been brewing throughout the nation's history" (Yong 2020).

As Yong's comprehensive essay shows, the data on these impacts are clear, as is the reality of systemic bigotry against persons of color, LGBTQ, the disabled, and the impoverished. It is also clear that those who bear the brunt of such bigotry will suffer more during this and future pandemics, just as they have suffered for decades in a health care system that favors privileged groups.

A medical emergency, however, is not the place to address these problems. Society moves into medical triage only during situations of extremis and one does the best one can in the face of a wide array of competing goods and evils. The triage room cannot be the setting to try to repair social injustice. Rather, structural, systemic flaws demand structural and systemic corrections that are transparent and auditable at the macro-level; real solutions to these real structural disparities can come only if addressed on the front end, through activist commitment to social reform, not during triage, as professionals struggle to do the most good with limited resources.

Further, tracing these injustices is empirically fraught, as it is obviously not the case that all persons from marginalized communities have suffered from injustices. And which communities? The conversation of the last several months has understandably focused on African-Americans: their per capita death rate from Covid-19 is by far the highest, some two and a half times that of whites, a figure "both tragic and wholly expected given the mountain of medical disadvantages that Black people face. Compared with white people, they die three years younger. Black people have higher rates of chronic illnesses that predispose them to fatal cases of Covid-19" (Yong 2020).

At the same time, the highest rates of infection are found in Latino-Hispanic populations, those who make up the bulk of "essential workers." They also cannot afford to miss work, often live in crowded multi-generational households, and heavily rely on pooled transportation. It is no surprise, thus, that as of early July their infection rate was the highest, greater than that among African-Americans and nearly triple that of whites (Oppel et al 2020). Further, death rates among Latino-Hispanics and Native Americans are a third higher than for whites (Anonymous 2020).

Which groups, thus, should be favored in triage protocols? All African-Americans? All Latino-Hispanics? All Native-Americans? How about Filipino-Americans, who are also suffering unusually high death rates (Wong 2020)? Or immigrants who have been blocked from both gainful employment and government assistance (Chishti and Bolter 2020)? Or maybe just all essential workers? At what point does 
triage become so inclusive as to be meaningless or so complex as to be impossible to apply?

Even if it was possible to coherently determine which groups should be given favored access to scarce resources, what method for assigning preference should be used? Early conversations among ethicists suggested an informal approach in which treatment or triage teams would quietly prioritize persons of color when facing a forced choice. This runs contrary to the core concept of triage, where the toughest allocation decisions are removed from treating professionals and where decisionmaking triage groups are blinded from any demographic data not directly relevant to likely survivability. Such blinding is done for very good reason: When has it ever been the case that persons of color, or other marginalized groups, have benefited from informal methods of favoritism? In the real world, the prevalence of bigotry means that persons of color, LGBTQ, the disabled, those in poverty, undocumented persons, and those who speak a different language will invariably be worse off when individual decision-makers are allowed, even encouraged to put a thumb on the scale. Small triage committees, formed ad hoc in individual hospitals during a crisis, are tasked with making a quick decision on triage eligibility. The medical risk/benefit data are complex and of uncertain reliability and availability. To further burden this committee with finding, vetting, and weighing more complex demographic data would make the situation unwieldly and chaotic. Real time auditing to assess for bias is unlikely to occur and, even when managed, too often would result in injustices toward marginalized groups.

What of more formal methods, like "weighted lotteries?" Douglas White and Derek Angus propose one for their state: "Individuals from disadvantaged areas, defined as residing at an address with an Area Deprivation Index score of 8 to 10 and ... essential workers, defined by the Commonwealth of Pennsylvania list of essential businesses that are required to continue physical operations during the pandemic" would be given 25 percent added weight in a centralized lottery system that determines who receives scarce resources (White and Angus 2020).

Attractive in principle, the model still suffers such ambiguities as to reduce it to arbitrariness: anyone who happened to live in a designated "disadvantaged area" would be granted greater access to scarce medical resources, regardless of whether they were personally disadvantaged, and truly disadvantaged persons living in the wrong zip code would be excluded. Preference in isolation is one thing, but again these decisions are being made in situations of forced choice; one person's benefit necessarily means another's loss.

The determination of "essential worker" is similarly troubling. When one reflects on all those on whom society has deeply relied in the last six months, the list is long: some, but not all, health care professionals, and some but not all government workers; impacted hospitals' and medical clinics' environmental, food services, IT, accounting, security, administrative and secretarial staff; grocery store workers; delivery drivers; police and firefighters; teachers; medical researchers; garbage collectors; gardeners; ... At what point does the list become so long as to undercut the distinguishing role at the heart of triage? Even assuming a valid list could be generated, there remains the question of how much weight to grant such persons. White and Angus (2020) settle, without corresponding justification, on 0.25. Absent 
justification, that percentage appears random, given the widely disparate impacts associated with being a resident of a disadvantaged community or associated with the different levels of risk and societal contribution attached to one's essential worker status.

As Solomon et al. (2020) note, others recognize these flaws-including groups who might in fact benefit from a preferential system. Some of those critics, however, take these flaws to mean that any prioritized triage model is fatally unjust:

Some disability rights advocates assert that in such circumstances, triage based on assessing patients' likelihood of benefit is fundamentally incompatible with respect for human dignity. Instead, they propose adopting a first-come, firstserved process. But that approach would leave many people with disabilities worse off; in particular, people facing transportation, communication, and other barriers to access could be systematically disadvantaged. (Solomon et al. 2020, p. e27(3))

Solomon, et al.'s conclusion is correct: as enticing as it might be to toss out prioritized triage, well-designed protocols, ones that favor those most likely to survive and that give prioritization to at least extreme cases of life-years preservation, will always be better than the alternatives. Random is not possible in the midst of an emergency; first-come-first-served will profoundly benefit privileged persons with greater logistical and economic resources; and those with some "in"-political status, power, relationships - will invariably jump to the front of the queue. That is, the most marginalized members of society, including persons of color and the disabled, will be much worse off without such protocols. No coherent model of justice can support any of these options.

In sum, carefully designed and implemented triage protocols balance the range of concerns: medical realities, number of lives saved, and protection of that which makes life worth living. None are perfect; all create difficult grey areas that demand ethical discernment.

To meet the challenges of a pandemic at both the macro-level and the microlevel, a key role for medical ethics is to encourage cooperation to increase beneficence. Ethicists need not invent anything new. Rather, they may focus on some of the fundamentals of ethics - telling the truth using unbiased facts, clarifying values to define common goals, and implementing plans fairly, transparently, and justly.

On September 28, 2020 the United Nations Secretary General António Guterres succinctly expressed (Guterres 2020) the ideas contained in this paper. "We must learn from the mistakes," he said. "Responsible leadership matters. Science matters. Cooperation matters — and misinformation kills."

\section{References}

American Academy of Pediatrics. (2020). COVID-19 planning considerations: Guidance for school reentry. Retrieved September 5, 2020, from https://services.aap.org/en/pages/2019-novel-coronaviru s-covid-19-infections/clinical-guidance/covid-19-planning-considerations-return-to-in-person-educa tion-in-schools/. 
Anderson, R., Camosy, C., Chisolm, M., Curlin, F., George, R., Glendon, M.A., Keown, J., Kheriaty, A., Lantos Swett, K., Lee, P., Mark, D., McHugh, P., Moschella, M., Rivers, J., Saunders, W., Tollefsen, C., Vogler, C., VanderWeele, T., West, C., \& Hamza Yusuf, S. (2020). Moral guidance on prioritizing care during a pandemic; joint statement. Public Discourse: The Journal of the Witherspoon Institute, April 4. Retrieved July 29, 2020, https://www.thepublicdiscourse.com/2020/04/62001/.

Anonymous. (2020). COVID-19 is affecting Black, indigenous, Latinx, and other people of color the most. The COVID Tracking Project. Retrieved August 2, 2020, https://covidtracking.com/race.

Antiel, R. M., Curlin, F. A., Persad, G., et al. (2020). Should pediatric patients be prioritized when rationing life-saving treatments during COVID-19 pandemic. Pediatrics, 146(3), e2020012542.

Association of American Medical Colleges. (2020). The way forward on Covid-19: A road map to reset the nation's approach to the pandemic. Retrieved August 3, 2020, https://www.aamc.org/covid roadmap/roadmap.

Barnes, P. (2020). Sentencing older COVID-19 patients to death by triage. Forbes, July 3. Retrieved July 27, 2020, www.forbes.com/sites/patriciagbarnes/2020/07/03/sentencing-older-covid-19-patients-todeath-by-triage/\#571ee77276b4.

Barnett, M., \& Grabowski, D. (2020). Covid-19 is ravaging nursing homes. We're getting what we paid for. Washington Post. 16 April 2020. Retrieved September 5, 2020, https://www.washingtonpost. com/opinions/2020/04/16/covid-19-is-ravaging-nursing-homes-were-getting-what-we-paid/.

Center, C. (2020). Letter to Gavin Newsom and Mark Ghaly from the Disability Rights Education and Defense Fund. April 22 (widely distributed via email and social media).

Cha, A. (2020). In New York's largest hospital system, many coronavirus patients on ventilators didn't make it. Washington Post 26 April 2020. Retrieved September 5, 2020, https://www.washington post.com/health/2020/04/22/coronavirus-ventilators-survival/.

Chishti, M. \& Bolter, J. (2020). Vulnerable to COVID-19 and in frontline jobs, immigrants are mostly shut out of U.S. relief. Migration Policy Institute. Retrieved August 6, 2020, from https://www. migrationpolicy.org/article/covid19-immigrants-shut-out-federal-relief.

Conover, C. (2020). How Economists Calculate The Costs And Benefits Of COVID-19 lockdowns. Forbes. 27 March 2020.

Contrera, J. (2020) The N95 shortage America can't seem to fix. Washington Post, 21 Sept 2020. Retrieved September 21, 2020, https://www.washingtonpost.com/graphics/2020/local/news/n-95shortage-covid.

Cornwall, W. (2020). Just 50\% of Americans plan to get a COVID-19 vaccine. Science. https://doi. org/10.1126/science.abd6018.

Covey, S. (2004). The 7 habits of highly effective people: Restoring the character ethic. New York: Free Press.

Dale, D. (2020). Fact check: McConnell claims Obama didn't leave Trump a pandemic "game plan." Obama left a 69-page playbook. CNN. 12 May 2020. Retrieved September 5, 2020, https://www. cnn.com/2020/05/12/politics/fact-check-mcconnell-obama-trump-game-plan/index.html.

Daniels, N. (1988). Am I my brother's keeper? New York: Oxford University Press.

Emanuel, E. J., \& Wertheimer, A. (2006). Who should get influenza vaccine when not all can? Science, New Series, 312(5775), 854-855.

EPA. (2020). Mortality risk valuation. United States Environmental Protection Agency. Retrieved September 5, 2020, https://www.epa.gov/environmental-economics/mortality-risk-valuation\#whatvalue.

Ferguson, N., Laydon, D., Nedjati Gilani, G., Imai, N., Ainslie, K., Baguelin, M., et al. (2020). Report 9: Impact of non-pharmaceutical interventions (NPIs) to reduce COVID19 mortality and healthcare demand. Oxford, UK: Imperial College. Retrieved September 5, 2020, https://spiral.imperial.ac.uk/ bitstream/10044/1/77482/14/2020-03-16-COVID19-Report-9.pd.

Fowler, G. (2020). A covid-fighting tool is buried in your phone. Turn it on. Washington Post 18 Nov 2020. Retrieved November 18, 2020, https:/www.washingtonpost.com/technology/2020/11/18/ coronavirus-app-exposure-alerts/.

FTC. (2020). FTC imposes $\$ 5$ billion penalty and sweeping new privacy restrictions on Facebook. Federal Trade Commission. 24 July 2019. Retrieved September 5, 2020, https://www.ftc.gov/newsevents/press-releases/2019/07/ftc-imposes-5-billion-penalty-sweeping-new-privacy-restrictions.

Guterres, A. (2020). Millionth death from COVID-19 "an agonizing milestone". UN News 29 Sept 2020. Retrieved January 20, 2021, https://news.un.org/en/story/2020/09/1074102, audio file.

Hardwig, J. (1997). Is there a duty to die? Hastings Center Report, 27(2), 34-42. 
Harris, J, Kristof, N, \& Ellick, AB. (2020). How America lost 200,000 lives to Covid-19. New York Times, 29 Sept 2020. Retrieved October 1, 2020, https:/www.nytimes.com/2020/09/29/opinion/ covid-pandemic-us-response.html.

Johns Hopkins University. (2020). The COVID-19 dashboard by the center for systems science and engineering at Johns Hopkins University. Retrieved September 5, 2020, https://coronavirus.jhu.edu/map. html.

Kyodo. (2020). Japan's coronavirus contact-tracing app launched amid privacy concerns. Japan Times. 19 Jun 2020. Retrieved September 5, 2020, https://www.japantimes.co.jp/news/2020/06/19/national/ japan-contact-tracing-app-launched/.

Lagu, T., Artenstein, A., \& Werner, R. (2020). Fool me twice: The role for hospitals and health systems in fixing the broken PPE supply chain. Journal of Hospital Medicine, 9, 570-571.

Lash, R. R., Donovan, C. V., Fleischauer, A. T., Moore, Z. S., Harris, G., Hayes, S., et al. (2020). COVID19 contact tracing in two counties-North Carolina, June-July 2020. MMWR: Morbidity and Mortality Weekly Report, 69, 1360-1363.

Maves, R. C., Downar, J., Dichter, J. R., Hick, J. L., Devereaux, A., Geiling, J. A., et al. (2020). Triage of scarce critical care resources in COVID-19: An implementation guide for regional allocation. CHEST Journal, 158(1), 212-225.

Michaels, D. (2008). Doubt is their product: How industry's assault on science threatens your health. Oxford: Oxford University Press.

Mihaljevic, T., \& Farrugia, G. (2020). How many more will die from fear of the coronavirus? New York Times, 06 June 2020. https:/www.nytimes.com/2020/06/09/opinion/coronavirus-hospitals-death s.html.

Miller, F. G. (2020). Why I support age-related rationing of ventilators for COVID-19 patients." The Hastings Center, April 9. Retrieved July 31, 2020, https://www.thehastingscenter.org/why-i-suppo rt-age-related-rationing-of-ventilators-for-covid-19-patients/.

National Security Council. (2020). Playbook for early response to high-consequence emerging infectious disease threats and biological incidents. Ann Arbor: Nimble Books.

New York Times, (2020). Deaths are linked to nursing homes. New York Times, Updated 16 Sept 2020. Retrieved September 30, 2020, https://www.nytimes.com/interactive/2020/us/coronavirus-nursinghomes.html.

Oppel, R. A., Jr., Gebeloff, R., Rebecca Lai, K. K. R. W., \& Smith, M. (2020). The fullest look yet at the racial inequity of Coronavirus. New York Times, July 5. Retrieved August 2, 2020, https://www. nytimes.com/interactive/2020/07/05/us/coronavirus-latinos-african-americans-cdc-data.html.

Oreskes, N., \& Conway, E. M. (2010). Merchants of doubt: How a handful of scientists obscured the truth on issues from tobacco smoke to global warming. New York: Bloomsbury Press.

Quote Investigator. (2020, March 17). Retrieved September 5, 2020, https:/quoteinvestigat or.com/2020/03/17/own-facts/.

Reilly, L. (2020). In combating COVID-19, science is how we get back to normal. PhRMA. 2020 June 24. Retrieved September 5, 2020, https://catalyst.phrma.org/in-combating-covid-19-science-is-howwe-get-back-to-normal.

Reinhard, B., \& Brown, E. (2020). Face masks in national stockpile have not been substantially replenished since 2009. Washington Post. 10 March 2020. Retrieved September 5, 2020, https://www. washingtonpost.com/investigations/face-masks-in-national-stockpile-have-not-been-substantiallyreplenished-since-2009/2020/03/10/57e57316-60c9-11ea-8baf-519cedb6ccd9_story.html.

Reinhart, R. J. (2020). More Americans now willing to get COVID-19 vaccine. Gallup, 17 Nov 2020. Retrieved November 17, 2020, https://news.gallup.com/poll/325208/americans-willing-covid-vacci ne.aspx.

Rivers, C., Martin, E., Watson, C., Schoch-Spana, M., Cicero, A., \& Inglesby, T. (2020 July). Resetting our response: Changes needed in the US approach to COVID-19. Baltimore, MD: Johns Hopkins Center for Health Security.

Rosenbaum, L. (June 11, 2020, published online Apr 17, 2020). The Untold Toll. New England Journal of Medicine, 382, 2368-2371.

Solomon, M. Z., Wynia, M. K., \& Gostin, L. O. (2020). COVID-19 crisis triage: Optimizing health outcomes and disability rights. New England Journal of Medicine, July 30, e27(1-3). Retrieved August 1, 2020, from https://www.nejm.org/doi/full/10.1056/NEJMp2008300.

Stone, J. (2020). Social justice, triage, and COVID-19: Ignore life-years saved. Medical Care, 58(7), $579-581$. 
Szabo, L. (2020). There's a legitimate way to end coronavirus vaccine trials early, Fauci says. CNN.2 September 2020. Retrieved September 5, 2020, from https://www.cnn.com/2020/09/01/health/coron avirus-vaccine-trials-early-fauci/index.html.

Wen, L. (2020). The U.S. is facing a crisis of confidence in our government scientists. Washington Post. 2 September 2020. Retrieved September 5, 2020, from https://www.washingtonpost.com/opini ons/2020/09/02/us-is-facing-crisis-confidence-our-government-scientists/.

White, D., \& Angus, D. C. (2020). A proposed lottery system to allocate scarce COVID-19 medications: Promoting fairness and generating knowledge. Journal of American Medical Association, 324(4), 329-330.

Wong, T. (2020). Little noticed, Filipino Americans are dying of COVID-19 at an alarming rate. Los Angeles Times, July 21. Retrieved August 6, 2020, from https://www.latimes.com/california/story /2020-07-21/filipino-americans-dying-covid.

World Health Organization. (2019). Ten threats to global health in 2019. Retrieved February 4, 2021, from https://www.who.int/news-room/spotlight/ten-threats-to-global-health-in-2019.

Yong, E. (2020). How the pandemic defeated America: A virus has brought the world's most powerful country to its knees. The Atlantic. August 4. Retrieved August 30, 2020, from https://www.theatlanti c.com/magazine/archive/2020/09/coronavirus-american-failure/614191/.

Publisher's Note Springer Nature remains neutral with regard to jurisdictional claims in published maps and institutional affiliations. 